\title{
nature
}

\section{Powerful visions for astronomy}

US astronomers are getting better at forming a collective view of priorities. Their latest wish list is worth fighting for, but it is the process used to generate it that gives the community the best chance of attracting the necessary funds.

$\mathrm{M}$ ore than 100 US astronomers have put their heads together and come up with a prioritized wish list for public investment in their field during the next decade (see page 381 ). This 'decadal review' of astronomy and astrophysics, produced under the auspices of the National Academy of Sciences, is to be applauded. It is one of science's most effective priority-setting exercises: a model for astronomers in other regions to follow and for other disciplines to consider.

The process is all-important. Washington is drowning in reports, and the last thing congressional staffers or White House budget examiners want is to settle differences among squabbling scientists. So a coherent approach within the community is essential for making others sit up and listen.

This has necessitated a year of full-time leadership by some key individuals. Each of the nine sub-panels — organized mostly by observational technique - held three meetings. There were also 'town meetings' and public sessions to gauge the community's views. Each sub-panel voted on priorities for its category, ranking projects primarily on their scientific usefulness.

These recommendations then went up to the main committee, which held five meetings over an 11-month period. All agree it was hard to make choices. Each of the sub-panel reports went through the full academy review process, and the 23 reviewers of the main report had credentials equal to anyone on the committee.

They generated 120 pages of comments - a painful process, but all part of shoring up the report's credibility. And the knowledge that this is a chance to feed one's ideas into such a well-regulated and influential process ensures that some of the best of the community's creative vision gets captured.

The plan presented last week contains plenty of exciting science. An 8-metre infrared telescope in space could look back to the dawn of the Universe to see the first galaxies that formed. Its ground-based companion, a 30-metre segmented telescope, would see protoplanetary disks as sharply defined rings instead of blurry blobs. The Terrestrial Planet Finder - which the committee would like to see get under way at least in the next decade — would be capable of finding the first Earth-like worlds.

The astronomers who served on the review committee believe that, in the coming decade, astronomy can lead the way in stimulating the public's interest in science. But the community will have to show that it is being frugal with public money. That leaves little room for duplicative projects or those born of institutional or national pride. The review panel is right to make a strong case for cooperation, not only among US astronomers and their international colleagues, but also between privately and publicly owned observatories.

The decadal review committee's plan would go a long way towards achieving that goal. We could look forward to having a powerful array of instruments scanning the Universe across the electromagnetic spectrum. Many of these projects are already planned to be international, which, like the survey itself, reflects a welcome maturity in the astronomical community.

The report also emphasizes the need to follow through with the recommendations of the last review while getting these new projects under way. The Atacama Large Millimeter Array, although approved, is the only one of that committee's four major recommendations that is not yet under construction. It must not fall by the wayside.

The presentation of this work is what matters now. There is going to be a glossy version of the report, published later this year, aimed at the general public. As for the leading astronomers who compiled the report, they will be astronomy's ambassadors. They've already met with the National Science Foundation and the space agency NASA, and will brief Congressional staffers and the Office of Management and Budget. As hard as they've laboured in the past year, in some important ways their work has only just begun.

\section{Values of the abstract}

A new set of prizes is an apt celebration of the significance and wonder to be found in pure mathematics.

66 have just one chance for escaping a verdict of complete triviality, that I may be judged to have created something worth creating. And that I have created something is undeniable: the question is about its value." As the great number theorist G. H. Hardy went on to conclude in A Mathematician's Apology, his work, producing nothing that was useful, had simply "added something to knowledge, and helped others to add more; and these somethings have a value which differs in degree only, and not in kind, from that of the creations of the great mathematicians, or of any other artists, great or small, who have left some kind of memorial behind them."

Science will grab anything that it can turn to its own ends, and plenty of seemingly useless mathematics has turned out to be essential for future breakthroughs. When Hardy wrote his book in 1940, physicists hadn't discovered the possible links between the Riemann hypothesis on the distribution of prime numbers and the statistics of eigenstates of quantum systems with underlying classically chaotic behaviour. And science poses fundamental mathematical challenges of its own, such as the unsolved Navier-Stokes equations of fluid dynamics and the Yang-Mills equations derived as a geometrical account of the fundamental forces between elementary particles.

All credit, then, to the Clay Mathematics Institute for celebrating the intrinsic value of such challenges. The institute has gone beyond the Fields Medal and the Wolf Prize in singling out long-standing mathematical problems - the three above, plus four others that are less obviously applicable - and valuing each of their solutions at US $\$ 1$ million (see page 383). It's an excellent way for a private foundation to recognize the eternal fascination that mathematics holds for people such as Hardy, and for the rest of us. 